\title{
PARTILHA DA APORIA: DIÁLOGOS COM ALBERTO PUCHEU
}

\section{Alberto Pucheu \\ Entrevista por: \\ Cleber Araújo Cabral* \\ Rafael Lovisi Prado**}

Como apresentar um rosto $\mathrm{e}(\mathrm{m})$ suas muitas faces e, ao mesmo tempo, escapar às capturas que uma rostificação implica? Funções, titulações, instituições, publicações, orientações: traços que, por um lado, permitem entrever a potência produtiva de nosso entrevistado - mas que, por outro, podem ocasionar o engendramento de semblantes encerrados na imobilidade dos signos, clausura que age justamente através desse mais de um rosto a que dão forma. Talvez então, nesta tarefa irremediável, seja melhor que ele se delineie nas orlas da poesia e da filosofi pelos murmúrios e marulhos que transitam pela voz daquele que, por hora, põe-se a falar. Deixar que ele se torne clandestino na fala que partilha conosco, que se ponha um pouco à deriva nas marés do diálogo que lhe foi proposto, às margens do disciplinar, nas arrebentações e aporias do contemporâneo.

\author{
* clabrac1980@gmail.com \\ *rafa lovisi@yahoo.com.br \\ Doutorandos em Teoria da Literatura e Literatura Comparada - \\ FALE/UFMG
}

NO ENSAIO “EFEITOS DO CONTEMPORÂNEO”, DE SEU LIVRO APOESIA CONTEMPORÂNEA, VOCÊ DIZ OUE NOSSO TEMPO “NÃO SE DEFINE POR UM PENSAMENTO ESPECÍFICO, MAS, ANTES, PELA ABERTURA DAS POSSIBILIDADES DO PENSAMENTO QUE DIZ RESPEITO A TODAS AS FORÇAS - IRRECONHECÍVEIS - NELE ATUANTES". ' COMO APROXIMAR (OU APRESENTAR) O OLHAR E O PENSAMENTO DESTA "MIRAGEM DO INFORME", "AGORA" MARCADO PELA ILEGIBILIDADE E RESISTÊNCIA À APREENSÃO, UMA VEZ QUE, "COMO A POESIA, O CONTEMPORÂNEO NÃO PODE SER ESSENCIALMENTE HISTORICIZADO SEM OUE ELE MESMO SE ELIMINE COMPLETAMENTE"??

O conceito de contemporâneo, com um valor atrelado a ele, é muitas vezes um termo em disputa, com uma pessoa se querendo "mais contemporânea" do que a outra, querendo que sua arte ou a de alguém valorizada seja "mais contemporânea" do que outras. Não é raro ouvir que uma das artes, as visuais, por exemplo, seja "mais contemporânea” do que outra,
PUCHEU, Alberto. Efeitos do contemporâneo. In: apoesia contemporânea, Rio de Janeiro: Azougue Editorial/ CAPES/FAPERJ, 2014, p. 325. Disponivel em: hitt://www. albertopucheu.com.br/pdr/ivros/ apoesiacontemporanea.pdf

2. PUCHEU, Alberto. Efeitos do contemporâneo. In: apoesia contemporânea, Rio de Janeiro: Azougue Editorial/CAPES/ FAPERJ, 2014, p. 326. 
como, por exemplo, a poesia. Entendo haver um grande equívoco aí, uma tentativa de se colocar, então, do lado do poder unilateral, perdendo a complexidade das movimentações da criação e do pensamento. O que digo no livro é que se o contemporâneo é inacessível, colocando-se como essa abertura incondicional de possibilidades que não pode ser apropriada nem fechada, nós temos acesso não exatamente a ele, mas a seus efeitos, àquilo que o contemporâneo produz. Daí o título de um dos ensaios do livro ser "Efeitos do contemporâneo". É com os efeitos que lidamos... e com a abertura inapropriável. Entendo ser um equívoco atrelar o contemporâneo a um de seus efeitos específicos como modo de domesticá-lo, como modo de perder sua complexidade maior, como modo de perder seu indizível, como modo de reduzir o tamanho, imenso, da abertura. Em relação diretamente à pergunta de vocês, eu responderia brevemente que, enquanto aqueles que criticam o contemporâneo ou o que é chamado de poesia contemporânea ou arte contemporânea parecem realizar exatamente uma tentativa de bloqueio, de atravancamento, de entulhamento ou de obstrução da abertura incondicional do contemporâneo, e enquanto outros querem garantir um "mais contemporâneo" atrelando o contemporâneo a alguns de seus efeitos, eu diria brevemente que o aspecto seletivo que mais me interessa é regido pelo princípio afirmativo (o único para mim capaz de ser usado neste caso) de serem escolhidos alguns dos efeitos que, ao trepidarem sobre o contemporâneo, mantêm a imanência do contemporâneo, inacessível, trepidando. É preciso garantir a todo custo esse inacessível, esse inapropriável, do contemporâneo, de modo que, não recalcando seu desimpedimento, ele retorne a cada momento como exclamação capaz de gerar possibilidades e perguntas que preservem sua abertura. É preciso dizer que só lidamos com o contemporâneo de modo singular e que este modo singular pelo qual cada um de nós é movido pela ideia do contemporâneo, aceitando-a cada um à sua maneira tal qual foi por ela impelido, se manifesta nos efeitos que a cada momento conseguimos imaginar; mas, mesmo tendo produzido um efeito qualquer do contemporâneo, se nossa vida é lançada no contemporâneo, é porque preferimos permanecer na força maior que caracteriza o intervalo entre a ideia do contemporâneo e seus efeitos.

RETOMANDO A QUESTÃO QUE DÁ TÍTULO AOS ENSAIOS 'UM CRÍTICO, PARA QUE SERVE?" E "DOIS CRÍTICOS, PARA QUE SERVEM?", O TEXTO CRÍTICO, PARA QUE (OU A OUEM) SERVE? E, EM ECO A BLANCHOT, PARA ONDE VAI OU EM OUE DIREÇÕES CAMINHA?

Os dois ensaios que vocês mencionam são certamente textos pares que abordam a questão por posições diametralmente opostas. O primeiro é um texto de combate a quem quer recusar em bloco tudo o que faz parte da poesia e da escrita contemporâneas; chega a ser lastimável que tal crítico (ou tais críticos), querendo abordar o contemporâneo, não se lembre(m) nem mesmo das palavras de Machado de Assis
3. Ambos publicados em PUCHEU, Alberto. $O$ amante da literatura. Rio de Janeiro: Oficina Raquel, 2010. Disponivelem: Raquel, oamantedaliteratura.pdf

\section{$\begin{array}{lllll}\text { EM TESE } & \text { BELO HORIZONTE } & \text { v. } 21 & \text { N. } 3 & \text { SET.-DEz. } 2015\end{array}$}

PUCHEU; CABRAL; PRADO. Partilha da aporia: diálogos com Alberto Pucheu

179-187 
4. Disponível em: http://www. albertopucheu.com.br/pdf/ivros/ pelo colorido.pdf em "O ideal do crítico": "A crítica, que, para não ter o trabalho de meditar e aprofundar, se limitasse a uma proscrição em massa, seria a crítica da destruição e do aniquilamento". O segundo texto mencionado tem como ponto de partida críticos que realizam o contrário do(s) anterior(es); os casos abordados nele realizam o que poderia chamar de uma crítica filosófica e de uma crítica poética, ou de uma crítica poético-filosófica ou filosófico-poética, que garantem a inacessibilidade e a inapropriabilidade do texto abordado ao mesmo tempo em que, com isso, se asseguram igualmente enquanto texto criador, como discurso primeiro, sem que haja qualquer discurso rebocado por outro. Para mim, os dois textos estão ainda atrelados a um terceiro, intitulado "Literatura, para que serve?" (do livro Pelo colorido, para além do cinzento; a literatura e seus entornos interventivos $)^{4}$, fazendo com que, de certo modo, crítica e literatura sejam experiências afins. Entendo o fazer crítico-teórico como um fazer literário. Poemas, diálogos, tratados, cartas, confissões, diários, ensaios, fragmentos, aforismos, seminários... foram modos, desde o princípio, a um só tempo de invenção teórica e poética. Não dá para separar essas dimensões. Nesse sentido, parece-me que tanto a crítica como a literatura, para ainda manter os dois termos, servem às intensidades da vida, constituindo-se como um caminho vital intensivo de modo a tornar vida real, de maneira a realizar vida. Para mim, há dois modos inultrapassáveis de se pensar a arte, a literatura, a poesia: um nos foi dado por
Nietzsche, em Nietzsche contra Wagner, ao se perguntar se "foi o ódio à vida ou o excesso de vida que aí se fez criativo"; outro, foi Bernardo Soares quem, no Livro do desassossego, nos ofereceu essa fórmula surpreendente: "Toda literatura consiste num esforço para tornar a vida real. Como todos sabem, ainda quando agem sem saber, a vida é absolutamente irreal, na sua realidade direta". Assim, penso que, como literatura, a crítica serve ao "excesso de vida que se [faz] criativo" e a "um esforço para tornar a vida real".

SOBRETUDO A PARTIR DA SEGUNDA METADE DO SÉCULO XVIII, ASSISTIMOS A UMA SEGMENTAÇÃO DISCIPLINAR DOS DISCURSOS QUE VERSAM SOBRE AS ARTES OU OUE, DE ALGUMA FORMA, GIRAM EM TORNO DESTAS. DENTRE AS DIVERSAS NOMENCLATURAS E POSSIBILIDADES DE SE APREENDER TAIS LINHAS DISCURSIVAS, PODEMOS CITAR AQUELA SUGERIDA POR MÁRIO PERNIOLA, NA QUAL ENCONTRAMOS A “TEORIA DOS ARTISTAS" (REFLEXÕES DOS PRÓPRIOS CRIADORES ACERCA DAS OBRAS ARTÍSTICAS), A "ESTÉTICA" (SEGMENTO FILOSÓFICO STRICTO SENSU, DE ELABORAÇÃO CONCEITUAL) E O "PENSAMENTO POETANTE” (EXPERIMENTAÇÕES DE CARÁTER HÍBRIDO, TALVEZ PRÓXIMAS ÀOUELAS EMPREENDIDAS POR NIETZSCHE E BLANCHOT). LEVANDO EM CONTA OS LIMITES APONTADOS POR ESTE CENÁRIO, EM OUE MEDIDA OS MURAMENTOS, AS REPARTIÇÕES DISCIPLINARES OU QUERELAS METODOLÓGICAS AINDA ASSOMBRAM OS ESPAÇOS TANTO DA CRIAÇÃO LITERÁRIA COMO DA CRÍTICA?

Sem sombra de dúvidas, essa tripartição dos modos de se pensar a arte em "teoria dos artistas", "estética" e
EM TESE
BELO HORIZONTE
v. 21
N. 3

PUCHEU; CABRAL; PRADO. Partilha da aporia: diálogos com Alberto Pucheu

179-187 
"pensamento poetante" ajudam a flagrar maneiras de se pensar a arte que alargam nosso horizonte. Nela mesma entretanto tenho dificuldades de enquadrar alguns dos pensadores que mais me movem. Contrariamente à leitura hegemônica, não consigo pensar em Platão, por exemplo, em um filósofo, se entendermos aí uma experiência que não seja já poética. Não sei onde colocar Platão nessa tripartição. Schlegel tampouco, se lembrarmos que em sua invenção do fragmento, junto com Novalis, o levou a escrever, caracterizando o marco histórico de sua e de nossa época tal como ele pensava: "O que se pode fazer, enquanto filosofia e poesia estão separadas, está feito, perfeito e acabado. Portanto é tempo de unificar as duas". Nietzsche tampouco; aos vinte e poucos anos, quase dois anos antes da primeira edição de O Nascimento da Tragédia, numa carta a Erwin Rohde, ele atesta que a miscigenação entre o filosófico e o artístico é o destino de seu pensamento cuja plena realização depende apenas de uma questão de tempo: "No momento, ciência, arte e filosofia crescem, simultaneamente, em mim, de tal maneira que, aconteça 0 que acontecer, engendrarei, qualquer dia, um centauro". Como em O Nascimento da Tragédia a ciência aparece submetida à arte, o centauro adquire, então, seu corpo biforme, monstruoso, instintivamente sábio, de filho híbrido gerado pela simultaneidade de arte e filosofia. Entre nós, a partir de Os sertões, pode ser traçada uma linha intensiva de desguarnecimentos de fronteiras entre o poético e o ensaísmo, entre aquele e o teórico, entre estes e a ciência, evidenciada, aliás, numa carta a José Veríssimo, através da frase completamente afirmadora daquilo de que tal livro, de modo decisivo, foi, entre nós, abrindo o século XX, precursor: "o consórcio da ciência e da arte, sob qualquer de seus aspectos, é hoje a tendência mais elevada do pensamento humano". Lembremos ainda que Euclides ainda salientou a diferença de sua escrita como um "estilo algo bárbaro", "destinado aos corações" e que "devem compreendê-lo admiravelmente os poetas". A partir de tudo isso, e de muito mais que não foi dito aqui, penso que vivemos um momento de possibilidade de exploração de uma inespecificidade nas artes e na crítica. A amiga e crítica argentina Florencia Garramuño tem feito um trabalho de grande importância nessa direção. Bem como Roberto Corrêa dos Santos. Bem como todos que ao longo de décadas vêm trabalhando com o "campo expandido" ou "campo ampliado", conceito de Rosalind Krauss. Além de poemas, poetas se abrem à realização de desenhos, vídeos etc. (vejam os exemplos de Victor Heringer, Marília Garcia, Ricardo Aleixo, Laura Erber e tantos outros). Eu mesmo tenho tentado, ainda que precariamente, além dos poemas e ensaios e dos interstícios possíveis entre eles, a fazer instalações e trabalhos em filmagens que sejam a um só tempo poéticos e teóricos (como é o caso, por exemplo, 
5. Disponível em: https:// Www youtube.com/ watch?V=FIAlxyfKOMc

6. http://gabrielacapper.wix.com/ audiovisual dos vídeos "Hermes, a tartaruga e a lira" 5 e "Arranjo em busca de um paradigma para relação entre o crítico literário e o poeta"). Esses e outros trabalhos intermídia tenho feito em colaboração com Gabriela Capper, ${ }^{6}$ que, por sua vez, tem feito trabalhos audiovisuais a partir de poemas contemporâneos.

NA ENTREVISTA INTITULADA ESSA ESTRANHA INSTITUIÇÃO CHA MADA LITERATURA, JACOUES DERRIDA DIZIA SONHAR COM UMA ESCRITURA OUE NÃO SERIA NEM FILOSOFIA, NEM LITERATURA, NEM MESMO UMA FORMA CONTAMINADA POR UMA NEM POR OUTRA, AINDA OUE MANTIVESSE A MEMÓRIA DA LITERATURA E DA FILOSOFIA EM SEU CORPO: A INDECIDIBILIDADE PERANTE OS GÊNEROS. COMO ESTE SONHO DO FILÓSOFO FRANCÊS, QUE DIZ DOS ATRAVESSAMENTOS E DAS PASSAGENS ENTRE OS VÁRIOS LUGARES DA LINGUAGEM, POVOA SUA OBRA?

Poderia dizer simplesmente que este é um dos sonhos mais fortes (ainda que não o único, claro) que "povoam", em diversos níveis, o que venho tentando fazer. Fico feliz que vocês tenham observado isso. Nesse ponto, entretanto, acerca do "como" esses "atravessamentos" e "passagens" dos "vários lugares da linguagem" se dão em minha "obra", preferiria mais escutar do que falar.

EM ALGUM LUGAR DE SEUS ESCRITOS, GIORGIO AGAMBEN DIZ QUE A LITERATURA E O PENSAMENTO TAMBÉM FAZEM EXPERIMENTOS, TAL COMO A CIÊNCIA. MAS, ENOUANTO ESTA ÚLTIMA
ALMEJA COMPROVAR A VERDADE OU FALSIDADE DE UMA HIPOTESE, A LITERATURA E O PENSAMENTO TERIAM HORIZONTES OUTROS, JÁ QUE SERIAM EXPERIMENTOS OUE NÃO AMBICIONAM A VERDADE. ADMITINDO-SE ESSA PERSPECTIVA, QUAL SERIA, PARA VOCÊ, A RELEVÂNCIA DE TAIS CONSTRUTOS ERRANTES?

Vou responder em grego-brasileiro, dessa vez. Seguindo Platão, que, no Teeteto, havia escrito ser o espanto a origem da filosofia, Aristóteles, na Metafísica, faz uma colocação decisiva, que me alimenta em muito do que faço, sendo uma dessas colocações que jamais me abandonam: "Através do espanto, pois, tanto agora como desde a primeira vez, os homens começaram a filosofar [...]. Mas aquele que se espanta e se encontra sem caminhos [em aporia] reconhece sua ignorância. Por conseguinte, o filômito é, de certo modo, filósofo: pois o mito é composto do admirável, e com ele concorda e nele repousa”. Parece-me haver, pelo menos, três assertivas em tal passagem. A primeira, inteiramente platônica: a de que, para haver filosofia, tem de haver espanto, pois é através dele que, desde sua origem até sempre que ela existir, a cada vez, inevitavelmente, a filosofia se faz; na segunda, para a sorte de todos nós, indo além do Platão citado, uma breve explicação de quando o espanto se dá: o espanto se instaura quando, imersos na aporia, imersos no impasse, imersos na ausência de alternativas a serem seguidas, reconhecemos nossa ignorância, mergulhando no não saber que a caracteriza; por fim, é exatamente o compartilhar dessa
EM TESE
BELO HORIZONTE
v. 21
N. 3

PUCHEU; CABRAL; PRADO. Partilha da aporia: diálogos com Alberto Pucheu

P. $179-187$ 
experiência do impasse e da ignorância, o compartilhar, portanto, da aporia, que faz com que o filósofo e o poeta, de alguma maneira, sejam o mesmo. Impasse, ignorância espanto, os nomes para dizer o impossível da poesia e da filosofia enquanto sua maior possibilidade. Os nomes para dizer a impotência da poesia e da filosofia, seu não saber o que dizer e dizer de dentro desse impasse, resguardando-o no que diz. Aristóteles conseguiu sintetizar e, criando, atualizar de modo absolutamente magnífico aí o que, de algum modo, atravessa a tradição grega. Logo após Tirésias revelar ser Édipo o assassino procurado pela morte de Laio, o coro, no verso 485, diz, em tradução de Trajano Vieira: "Aporia dizer o quê?". Diante do quê, a contragosto, se mostra, diante do mais inquietante ou do terrível, diante do insuportável, diante do inaceitável, diante do real, que não se pode com tranquilidade aceitar nem refutar, diante do que, apesar da necessidade, não se consegue dizer, ou só se o diz pela falta de o quê dizer, eis o coro, desarticulado em um impasse diante de uma vida, a vida do personagem Édipo. Se, como diria Derrida em Morada, a literatura, moderna por excelência, poderia ser pensada como "o nome sem a coisa", a poesia, ao menos a grega, ao menos como a interpretada desde a interrogação do coro, coloca sua ênfase na aporia da coisa sem o nome. Na tragédia, o coro indica pensar que a experiência da vida do personagem Édipo é a que mais precisaria ser dita, mas é ela mesma que não permite que se encontre, na abertura da passagem, uma saída para dizê-la, gerando o impasse afirmado, que oblitera qualquer possibilidade de encontrar palavras para dizê-la, apesar de ser nessa direção que ele - o coro - tenta ir. Para mim, é ainda essa aporia, essa ignorância e esse espanto que garantem a errância, a instabilidade, as experimentações que, como vocês disseram, "não ambicionam a verdade", se por verdade se entende algo do âmbito de uma positividade garantida qualquer.

NO VÍDEO “ARRANJO EM BUSCA DE UM PARADIGMA PARA A RELAÇÃO ENTRE O CRÍTICO LITERÁRIO E O POETA", ASSISTIMOS SURFISTAS SE COLOCANDO EM SITUAÇÕES LIMITES, INSINUANDO-SE EM ONDAS GIGANTES, "EXCEDENDO OS LIMITES DA PRÓPRIA ONDA E DE SUAS REGRAS NÃO ESTABELECIDAS". EM MOMENTO ALGUM, NO TEXTO QUE VOCÊ LÊ NO VÍDEO, SÃO MENCIONADOS O CRÍTICO LITERÁRIO E O POETA. NAS PRÁTICAS DE AMBOS, COMO NO SURF, SÃO MOVIMENTOS EM QUE CORPO E PENSAMENTO CONFLUEM EM PERFORMANCES POR TERRITÓRIOS SEMOVENTES (O MAR, A LINGUAGEM). SENDO BOXE, SURF, ENSAÍSMO, FILOSOFIA, CRÍTICA E POESIA ALGUMAS DAS ONDAS QUE VOCÊ PEGA, GOSTARÍAMOS QUE VOCÊ FALASSE DESSAS PARCERIAS E SUAS DOBRAS - POESSURFIA, FILOSSURFIA. COMO UMA COLOCA A OUTRA EM RISCO, EXPANDE E/OU REFLUI NA OUTRA? RETOMANDO O VÍDEO, OUEM PILOTA O JET SKI - CRÍTICO, ENSAÍSTA, FILÓSOFO OU POETA? SE O “OCEANO É O LIVRO DO SURFISTA, SUA PRANCHA UMA CANETA, E CADA ONDA UM POEMA", ${ }^{8}$ SERIA A POESIA OS OCEANOS, O POETA UM DE SEUS HABITANTES E UMA FOLHA (OU UMA TELA) A PRANCHA NA OUAL DESLIZA PELAS CORRENTES SUBMARINAS?
7. LINS, Daniel. Deleuze: o surfista da imanência. In.: LINS, Daniel; GIL, José. Nietzsche/ Deleuze:

Forense Universitária, 2008, p. 53.

8. LINS, Daniel. Deleuze: o surfista da imanência. In.: LINS, Daniel; GIL, Jose. Nietzsche/ Deleuze: jogo e música. Rio de Janeiro: 
Gostaria de dizer que, como está já no título, esse vídeo a que vocês se referem é um arranjo, arranjo, no caso, textua e imagético. Chamo de arranjo escritos (ou no caso audiovisuais) em que não há nenhuma palavra minha. No caso, todas as frases foram colhidas das bocas de surfistas, em filmes, livros, depoimentos etc. São eles que falam e eu simplesmente escuto e arranjo. Os arranjos são então um gesto de escutar, selecionar, copiar, colar, ordenar, citar, deslocar, repetir de modo diferenciado em novo contexto, repetir, portanto, de modo diferenciado. Esse audiovisual é o primeiro que Gabriela Capper e eu fizemos, o primeiro em parceria o primeiro para cada um de nós individualmente também. Depois, fizemos outros juntos, bem como ela fez vários sozinha e eu alguns por minha conta, mas com ela fazendo sempre a edição. Nesse a que vocês se referem, não filmamos nada; a lógica do arranjo do texto também se deu para as imagens, todas colhidas da internet. $\mathrm{Na}$ sonorização, sem que a Gabi soubesse, eu havia pensado em testar Ionization, de Edgar Varèse, enquanto ela, sem que eu soubesse, havia pensado em testar "Tundra's song” (Prelude), da banda Yat Kha, formada em 1991, em Moscou, que une música tradicional russa e rock. Quando conversamos e descobrimos isso, na experimentação acabamos por chegar à sobreposição ou fusão das duas faixas e gostamos do resultado, que funde o arcaico e o contemporâneo em um ritmo que parece ficar à altura da intensidade das imagens dos surfistas pegando aquelas ondas de até trinta metros, que é absurda. Vocês afirmam com razão que em nenhum momento do texto o poeta e o crítico literário são mencionados; em nenhum momento, eu simplesmente salientaria para quem não conhece o trabalho, senão no título, que, exatamente por isso, é minha única intervenção para além do próprio gesto de arranjar. A ideia era mesmo essa, a de criar pelo título e pelo arranjo um modo de falar da busca de uma relação entre o crítico e o poeta que viesse de um outro lugar em que se dá o encontro das duplas, o modo agir de dois que precisam trabalhar em conjunto, como os surfistas, como o crítico e o poeta. Vocês perguntam quem pilota o jet ski e um dos pontos de grande interesse para mim é que o lugar do piloto e o lugar do surfista são intercambiáveis, ambos são piloto e ambos são surfistas exímios. No caso, ser sufista significa ser piloto e vice-versa, aprender em ambos os movimentos a lidarem com as situações mais extremas possíveis, sob o risco da morte. No caso do tow in, não é quem no momento está na prancha que escolhe a onda que ele mesmo vai pegar, mas quem está no jet ski, que o vai salvar ao fim da onda. Um trabalho de parceria total, que me parece de fato paradigmático para se pensar a relação entre o poeta e o crítico, tal como tenho tentado pensar. Não gostaria de fazer uma interpretação do audiovisual justamente por ter escolhido em, pelos procedimentos utilizados, manter as possibilidades abertas. Mas gostaria de fato que esse modo estimulasse 
o pensamento de críticos e de poetas de nosso tempo; acho que tem algo extremamente necessário aí para a escrita do nosso tempo. Como vocês falam do boxe, assim como há série dos poemas do surfe, há também uma série de poemas do boxe e, nela, um arranjo, só com frases de boxeadores. Em relação a última pergunta de vocês, serei breve. A navegação ocorre desde milênios, e eu acho incrível como os surfistas diminuíram drasticamente o tamanho daquilo que separa o homem do oceano nas condições mais adversas. Dos barcos e navios às pranchas a redução é drástica. Nas condições em que esses surfistas se colocam muitos navios naufragaram, partiram etc. E eles estão ali com apenas dois metros de prancha, ou um pouco mais, a separarem-nos da morte. A prancha me parece o verso, a linha, o caminho em movimento do poema a, com todos os riscos, cortar o informe abissal que quer deixar sua marca nela.

DESDE A DÉCADA DE 1990 TEMOS VISTO INTERPRETAÇÕES MELANCÓLICAS, NECROLÓGICAS E TRÁGICAS, FOCADAS NAS CRISES, OBITUARIOS E PERIGOS OUE RONDAM O PENSAMENTO E A LITERATURA. SENTENCIOU-SE A MORTE DA CRÍTICA, FALA-SE NA MUSA FALIDA, NO OCASO DA LITERATURA BRASILEIRA, LAMENTA-SE A PERDA DA CENTRALIDADE, NO CAMPO DA CULTURA, DA LITERATURA E DA CRITICA LITERÁRIA PARA OS MEIOS AUDIOVISUAIS E DIGITAIS. NA CONTRAMÃO DESSES DISCURSOS, VEMOS ESFORÇOS ATENTOS ÀS POTÊNCIAS DA CIRCUNSTÂNCIA CONTEMPORÂNEA E SEUS DESDOBRAMENTOS EM CONCEPÇÕES
EXPANSIVAS E RENOVADAS DE CRITICA E DE LITERATURA; FESTAS E FESTIVAIS SE MULTIPLICAM, POVOADOS POR UM PÚBLICO CRESCENTE; SOME-SE A ISSO A AUTOPUBLICAÇÃO E O SURGIMENTO DE PEQUENAS EDITORAS COM PROPOSTAS OUSADAS. DIANTE DESSE CENÁRIO, ENSINAR E FAZER LITERATURA, HOJE (NO BRASIL, AINDA MAIS ESPECIFICAMENTE), PARA QUÊ?

O pensamento do fim, tão presente na filosofia e no pensamento das artes desde ao menos Hegel no século XIX levou, junto com o pensamento da morte de Deus, de Nietzsche, a imensas aberturas no século XX. No que diz respeito à arte, Hegel e Nietzsche são pensadores com determinações antagônicas em muitos casos, provocando duas linhagens das mais fortes no século XX: de um lado, a da superação da arte pela filosofia, de outro, uma filosofia em seu devir artístico. Isso diz muito do século XX. Na literatura ou no cinema, as vanguardas anunciaram diversas mortes e fins. No primeiro filme de Guy Debord, está lá o fim do cinema, bem como ao longo de toda a trajetória de Godard o fim, a morte, o desaparecimento, o adeus... É uma constante nas vanguardas do século XX. Pensar o fim que não deixa de se anunciar sem, entretanto, chegar, senão por seu anúncio. Penso que esse fim se dá sempre em nome do fim de um específico ou de um próprio da arte em nome de um novo específico qualquer. No caso do cinema, parece-me significativo que os dois maiores cineastas do fim, os dois mencionados, foram os que levaram a montagem a seu extremo, radicalizando-a 
a tal ponto que fizeram filmes apenas com montagem, como se ela fosse o próprio do cinema. De algum modo, Godard leva ao extremo o pensamento do cinema russo dos anos 1920 (sobretudo Vertov, mas a ideia de montagem como fenômeno primordial do cinema também em Eisenstein e outros), fechando um ciclo da arte revolucionária ou utópica da revolução. Não tenho como não pensar que sempre que se fala em origens e fins trata-se de algum modo de um pensamento messiânico, religioso, determinado pelo gênesis e pelo apocalipse. Há todo um cinema desde então, penso, sobretudo, em Tarkóvski e Sokurov, que não aceitam mais nenhum próprio do cinema, que o cinema é impróprio, inespecífico, aberto ao que vem. Há todo um pensamento, como o de Deleuze, por exemplo, que se dá pelo meio. A literatura brasileira também se dá pelo meio, ela começa pelo meio de outras, Clarice começa um livro com reticências e por aí vai. As reticências indicam que algo já está aí, que se pega a onda já pelo meio, que se voa de asa delta já com a corrente de ar tendo começado, as reticências indicam igualmente toda a impossibilidade de dizer, um dizer que jamais se totaliza, lacunar, em falta, cesurado, rachado. É de dentro dessa racha, dessa fissura, dessa fissura pela racha, dessa fissura pela falta, dessa impotência do dizer que me parece estar a força hoje da literatura e da filosofia, em um mundo cheio de verdades totalizantes por todos os lados. 